\title{
PROMOÇÃO DO LETRAMENTO VERSUS MEDICALIZAÇÃO NO ENSINO SUPERIOR: CONTRIBUIÇÕES DE UMA ABORDAGEM FONOAUDIOLÓGICA
}

\author{
PROMOCIÓN DELLETRAMIENTO VERSUS LA MEDICALIZACIÓN EN LA \\ EDUCACIÓNSUPERIOR: CONTRIBUCIONES DE UN ABORDAJE \\ FONOAUDIOLÓGICO
}

\section{PROMOTING LITERACY VERSUS MEDICALIZATION ON HIGHER EDUCATION: SPEECH THERAPY CONTRIBUTIONS}

\author{
Sammia Klann VIEIRA ${ }^{1}$ \\ Rita de Cássia TONOCCHI ${ }^{2}$ \\ Ana Paula BERBERIAN ${ }^{3}$
}

RESUMO: Dentre as mudanças que vem ocorrendo no Ensino Superior brasileiro em função da expansão do ingresso de pessoas nesse nível de formação, interessa destacar a heterogeneidade dos acadêmicos quanto às diversas e desiguais condições de letramento. Parte-se do pressuposto de que tais condições são determinantes para a efetiva acessibilidade e para uma formação acadêmico-profissional de qualidade. O objetivo desta pesquisa foi analisar as contribuições de uma abordagem clínica fonoaudiológica baseada na perspectiva sócio-histórica, junto a um acadêmico diagnosticado como disléxico, enfocando aspectos discursivos, textuais e normativos da linguagem escrita. Trata-se de um estudo de caso, de cunho qualitativo, longitudinal e retrospectivo. Essa mudança permitiu ao sujeito reconhecerse como autor, ocupar um lugar de leitor e escritor capaz e entender a sua relação com a linguagem escrita como um processo contínuo, social e historicamente constituído.

\section{PALAVRAS-CHAVE: Ensino Superior. Fonoaudiologia. Letramento. Dislexia.} Medicalização.

RESUMEN: La expansión del ingreso de estudiantes brasileños en la educación superior está promoviendo cambios como la heterogeneidad de académicos con distintas y desiguales condiciones de letramiento. Se supone que estas condiciones determinen la real accesibilidad, así como una formación académico profesional de calidad. El objetivo de este trabajo fue investigar las contribuciones de un abordaje clínico fonoaudiológico, basado en la perspectiva histórica $y$ social, hecho, a su vez, en colaboración con un académico diagnosticado como disléxico, con el fin de caracterizar aspectos discursivos, textuales y

\footnotetext{
${ }^{1}$ Universidade Tuiuti do Paraná (UTP), Curitiba - PR - Brasil. Mestrado em Distúrbios da Comunicação. Apoio Financeiro da Coordenação de Aperfeiçoamento de Pessoal de Nível Superior- Brasil (CAPES) - código de financiamento 001. ORCID: https://orcid.org/0000-0002-3593-5004. E-mail: sammia.klann@gmail.com

${ }^{2}$ Universidade Tuiuti do Paraná (UTP), Curitiba - PR - Brasil. Professora do Curso de Graduação em Fonoaudiologia e no Programa de Pós-graduação em Distúrbios da Comunicação. Doutorado em Estudos Linguísticos (UFPR). ORCID: https://orcid.org/0000-0001-7006-0541. E-mail: rita.tonocchi@utp.br ${ }^{3}$ Universidade Tuiuti do Paraná (UTP), Curitiba - PR - Brasil. Professora no curso de Graduação em Fonoaudiologia e no Programa de Pós-graduação em Distúrbios da Comunicação. Doutorado em História (PUC/SP). Apoio Financeiro CNPQ/Produtividade em Pesquisa. Processo $\mathrm{N}^{\circ}$ 306523/2017-5. ORCID: https://orcid.org/0000-0001-7176-7610. E-mail: ana.berberian@utp.br
} 
normativos de su lenguaje escrito. Este es un estudio de caso cualitativo, longitudinal y retrospectivo. La perspectiva teórico-práctica adoptada promovió un cambio de la posición del paciente acerca de los factores limitantes de su letramiento: desde una perspectiva de medicalización e incapacidad, comenzó a analizar críticamente los determinantes macroestructurales que establecen esta condición. Este cambio permitió al sujeto reconocer a sí mismo como autor, lector y escritor capaz de percibir su relación con el lenguaje escrito como un proceso continuo, social e históricamente constituido.

PALABRAS CLAVE: Educación superior. Fonoaudiología. Letramiento. Dislexia. Medicalización.

ABSTRACT: A lot of changes occur on Brazilian higher education. One of then that we shed some light in this paper is the heterogeneity of undergrad students about their literacy conditions. Those conditions seen to be play an important role to provide an effective accessibility and a desirable academic-professional training to the students. The goal of this research is to analyze the speech therapy contributions based on socio-historical approach. The research is a qualitative, longitudinal and retrospective case study of one subject diagnosed as dyslexic. The corpus focus on discourse an text characteristics of writing. The theoretical driven praxis adopted promote to the subject a view change about their own literacy conditions. The subject gave up from an inability and medicalization view to begin to critically analyze the macro-structural reasons of his literacy condition. This change provide to recognize himself as author, reader and writer able to understand his role in the writing process. This process are continuous, social and historically constituted.

KEY-WORDS: Higher education. Speech therapy. Literacy. Dyslexia. Medicalization.

\section{Introdução}

O cenário do Ensino Superior (ES) no Brasil vem, especialmente a partir da década de 1990, sofrendo mudanças de natureza estruturais e conceituais provocadas por políticas e programas de acessibilidade, pela ampliação do número de vagas, pela abertura de cursos e instituições, por ações afirmativas, as quais tem gerado uma série de desafios provocados pela diversidade educacional, econômica e cultural da população de ingressantes (MANCEBO; VALE; GOMES, 2015).

Comprometidos com o enfrentamento de tais desafios, estudos apontam que apesar da importante expansão no número de ingressantes nas Instituições de Ensino Superior (IES), o direito a esse nível de formação ainda está restrito a uma parcela pequena da população brasileira. Tais estudos evidenciam que, problemas, de diferentes ordens, precisam ser enfrentados para garantir a permanência e a qualidade de tal formação, considerando as condições desiguais e diversas dos acadêmicos quanto: - ao acesso a bens materiais e culturais, - às experiências e trajetórias escolares; e às condições de letramento. Cabe destacar 
que esse crescimento envolveu, especialmente, pessoas menos favorecidas economicamente, as quais, em muitos casos, representam a primeira geração a ingressar nesse nível de formação (GOMES, 2015; MARINHO-ARAUJO, 2015; MANCEBO; VALE，2015; MORRETTO, 2017).

Assim, o ingresso no ES de grupos populacionais cada vez mais heterogêneos tem causado inquietações e convocam as IES a revisitarem concepções e práticas que tendem a conceber o alunado de forma homogênea (LUSTOSA et al., 2016; PAN; LITENSKI, 2018; SIGNOR et al., 2018)

Contrários a esse modo de abordar a problemática em questão, interessa destacar o abismo existente entre as expectativas de um desempenho satisfatório atribuídas aos alunos quanto às suas possibilidades de escrita e de leitura de textos acadêmicos e as reais condições de responderem às mesmas. Pesquisas de grande escala, bem como circunscritas a contextos específicos, evidenciam que um número restrito de alunos possui nível de letramento suficiente para atender as demandas próprias do ES e lugar crítico e de autoria no processo formativo (BENEVIDES, 2011; INSTITUTO ABRAMUNDO, 2014; GOMES，2015; MARQUESIN; SANTANA et al., 2016).

O reconhecimento da gravidade dessa situação está assentado no pressuposto de que as condições de letramento, ou seja, as relações e usos estabelecidos, histórica e coletivamente, com a linguagem escrita, podem promover ou restringir a acessibilidade a todos os alunos nas diferentes modalidade e níveis de formação escolar, entendendo que a garantia de tal acessibilidade pressupõe isonomia no ingresso, na permanência e na qualidade de ensino (MARINHO-ARAUJO, 2015; PAN; LITENSKI, 2018).

Contudo, pode-se acompanhar, por um lado, o número incipiente de estudos que ofereçam referenciais teórico-práticos para o enfrentamento, institucional e coletivo, do impacto formativo decorrentes das distintas condições de letramento apresentadas pelos alunos e, por outro, o predomínio de visões reducionistas na abordagem de tal problemática, uma vez que:

- atribuem, exclusivamente, aos alunos a responsabilidade por supostas limitações que comprometem o desempenho acadêmico, desconsiderando a reciprocidade estabelecida entre fatores macro e microestruturais, ou seja, entre aspectos econômicos, culturais e políticos e singularidades na constituição dos sujeitos e nas condições dos universitários enquanto falantes, leitores e escritores (PAN; ZUGMAN, 2015; MARINHO-ARAUJO, 2015; SANTANA et al., 2016). 
- de visões e intervenções medicalizantes que associam restritas/negativas relações vivenciadas por uma parcela significativa dos universitários com a leitura e escrita de textos pertencentes ao gênero acadêmico, a problemas inerentes aos mesmos e de natureza orgânica e/ou cognitiva e/ou psíquica (MOYSES; COLLARES, 2013; OLIVEIRA; HAYAMA; VIÉGAS, 2016).

Nessa direção, é possível acompanhar o aumento crescente de encaminhamentos para atendimento clínico fonoaudiológico de alunos inseridos no ES considerados com dificuldades e/ou distúrbios de leitura e escrita. Para o enfrentamento das demandas geradas por esse crescimento, bem como pelo número expressivo de alunos que se encontram em estado de sofrimento por não terem desempenho acadêmico adequado e relações negativas com a linguagem escrita, pode-se recorrer a estudos embasados na perspectiva sócio-histórica. Dentre tais estudos, interessa destacar aqueles produzidos no campo da Fonoaudiologia, direcionados ao contexto clínico e/ou educacional, que objetivam discutir possibilidades dos sujeitos, marcados pelo estatuto da incapacidade/deficiência, ressignificarem histórias vividas e mediadas pela linguagem escrita e, dessa forma, ocuparem um lugar de autoria nos processos educacionais em que estão inseridos (SIGNOR et al., 2018; LUSTOSA et al., 2016; GENTIL, 2016).

Com base em pilares teóricos dessa perspectiva, ou seja, na superação da dicotomia estabelecida entre o individual e o social, bem como no enfrentamento das contradições e dos distintos interesses e posições ideológicas constituídos e constitutivos dos discursos e das formas de organização social (BAKTHIN, 1990; GERALDI, 2013; ROJO; MELO, 2017), o trabalho clínico fonoaudiológico pode representar uma possibilidade dos referidos alunos abordarem a sua condição singular como constituída por determinantes amplos. Dessa forma, contribuir para ampliação de uma consciência assentada na noção de que a história de cada um ecoa a história de um grupo, de um tempo, desvelando aspectos culturais, econômicos e políticos em razão dos quais essas histórias foram e estão inscritas (SIGNOR, 2012; GENTIL, 2016; SIGNOR et al., 2018).

Essa abordagem convoca o fonoaudiólogo, no contexto clínico, a estabelecer como objetivo a ressignificação, por parte de alunos inseridos no ES, de relações de sofrimento com a linguagem escrita, com a condição de leitor e escritor, bem como, da culpa pelo pouco conhecimento e familiaridade com textos acadêmicos. Dessa forma, pode contribuir com a promoção do letramento e do processo de ensino-aprendizagem, abordando, simultaneamente, as dimensões discursivas, textuais e normativas que compõem a linguagem escrita e, portanto, 
seus processos de apropriação e uso (SIGNOR, 2012; ROJO; GENTIL, 2016; MELLO, 2017; SIGNOR et al., 2018).

Quanto à dimensão discursiva da linguagem escrita, cabe elucidar que os enunciados são sempre históricos e sua historicidade é captada no próprio movimento linguísticodialógico de sua constituição, ou seja, nas atividades/relações humanas se configuram a qualidade das mediações estabelecidas entre os interlocutores e o texto escrito. Com quem, para quem, com que finalidade os discursos são escritos e onde circulam definem condições de produção, as quais pressupõem diferentes estruturas textuais (aspectos composicional, temático e estilo) denominadas de gêneros do discurso (BAKTHIN, 1990, GERALDI, 2013; ROJO; MELO, 2017).

Já a dimensão textual envolve processos linguísticos, denominados coerência e coesão, relacionados à maneira como o sujeito elabora e articula as partes do texto de forma que possam ser apreendidos significados e construídos sentidos (KOCH; TAVAGLIA, 2006). A coesão e a coerência são fatores interligados para o estabelecimento de uma unidade de sentido que contemple uma progressão temática que responda à finalidade de uma determinada situação dialógica. É importante destacar que o sentido do texto não está dado $a$ priori, este se constrói na interação estabelecida entre o texto e os interlocutores (GERALDI, 2013; KOCH; TAVAGLIA, 2006).

A dimensão normativa envolve padrões gráficos, ortográficos e gramaticais definidos a partir de normas instituídas. Dentre tais padrões discorreremos acerca dos aspectos ortográficos da língua portuguesa. Considera-se que o sujeito utiliza estratégias e hipóteses que podem resultar manifestações fora do padrão, reveladoras de seus modos de se relacionar com o sistema ortográfico da língua (FARACO, 2012).

Feitas tais considerações, ressalta-se que o objetivo desta pesquisa é analisar as contribuições de uma abordagem clínica fonoaudiológica, baseada na perspectiva sóciohistórica, junto a um acadêmico diagnosticado como disléxico, enfocando aspectos discursivos, textuais e normativos que constituem a linguagem escrita.

\section{Procedimentos metodológicos}

Nesta seção objetiva-se explicitar aspectos relativos ao tipo e desenvolvimento da pesquisa, a caracterização do participante em relação à sua trajetória escolar, bem como a queixa motivo de seu encaminhamento para atendimento fonoaudilógico.

O presente estudo, aprovado pelo Comitê de Ética em Pesquisa, do tipo qualitativo, 
longitudinal e retrospectivo, configura-se como um estudo de caso que, a partir da perspectiva sócio-histórica, foi desenvolvido com base no atendimento clínico fonoaudiológico, junto a um aluno inserido no ES. Foi desenvolvida após a assinatura do Termo de Consentimento Livre e Esclarecido pelo participante, denominado com o nome fictício de João (J.). O aluno foi encaminhado para atendimento fonoaudiológico devido a queixas referentes à linguagem escrita, pelo Núcleo de Acessibilidade da Universidade pública que estuda. O atendimento clínico foi realizado semanalmente, em encontros com duração média de uma hora, na Clínica Escola de Fonoaudiologia de uma IES privada do Sul do Brasil. Para análise dos resultados foram considerados 20 meses de atendimento, desde o seu início, em maio de 2017, até dezembro de 2018. Os dados foram coletados durante as sessões realizadas, a partir de gravações em áudio no aparelho SM-G6100, versão MP 0.400.

O participante da pesquisa, denominado como J., tem 26 anos, nasceu em uma cidade do Sul do país e, no momento da pesquisa, morava numa cidade litorânea do Paraná. Quanto ao contexto familiar, J. estabelece vínculo com sua mãe, que é diarista, e com seus irmãos (um de 29 e outro de 25 anos). Ambos residem em outra cidade do Paraná, distinta da que J. reside, e são formados no ES tecnólogo. Durante o processo terapêutico, o pai de J., de 63 anos, com o qual ele não estabelecia contato há muitos anos, passou a residir e depender financeiramente do mesmo, por estar desempregado.

O participante da pesquisa possui uma namorada há, aproximadamente, seis anos, residente em uma cidade do Paraná distinta da sua. J. afirma que foi ela que o incentivou a voltar a estudar e a procurar ajuda de diversos profissionais para superar suas dificuldades relacionadas a questões emocionais e à linguagem oral e escrita.

Quanto aos aspectos relacionados à sua trajetória de vida, J. afirma que, durante a infância e a adolescência, passou por momentos de grande carência financeira, os quais não foram favoráveis ao seu desenvolvimento de forma geral e, em especial, à sua escolaridade. J. trabalha desde sua adolescência e hoje desempenha a função de jardineiro e serviços gerais como autônomo. Embora sua condição financeira tenha melhorado, comparada à vivida em sua infância e adolescência, J. declara passar por dificuldades, pois precisa trabalhar e conciliar essa atividade com seus estudos.

Acerca da queixa, que fundamentou o encaminhamento para a clínica fonoaudiológica, J. relatou que foi diagnosticado, por volta dos 12 anos de idade, como disléxico e com TDAH, pelo Núcleo de Educação. Quando solicitado, informou que não dispunha mais dos laudos referentes àquele período, mas pode nos fornecer documentos que reiteram tais diagnósticos; conforme demonstrado no quadro abaixo: 
Quadro 1 - Relatórios produzidos por profissionais da saúde e da educação

\begin{tabular}{|l|l|}
\hline RELATÓRIO/ANO & \multicolumn{1}{|c|}{ PARECER/ LAUDO } \\
\hline Psicoeducacional/2004 & $\begin{array}{l}\text { "De acordo com os dados obtidos na avaliação, XXXX deverá } \\
\text { permanecer no Ensino Regular com atendimento paralelo em Sala } \\
\text { de Recursos elou atendimento pedagógico. Recomenda-se também } \\
\text { avaliação neurológica, atendimento psicológico e continuidade no } \\
\text { atendimento fonoaudiológico". }\end{array}$ \\
\hline Fonoaudiológico/2011 & "Em face ao exposto e ao histórico de XXXX, os dados sugerem um \\
& Transtorno Específico de Leitura (CID F81.0), o que recomenda \\
& um apoio especifico na esfera acadêmica permitindo sua inserção \\
& no contexto escolar". \\
\hline Atestado Neurológico/2015 & $\begin{array}{l}\text { "Atesto para os devidos fins que o Sr. XXXX foi atendido por mim, } \\
\text { devido a Défict de Atenção, com medicação. Ex. neurológico com } \\
\text { déficit de atenção leve. Cid 10: F90". }\end{array}$ \\
\hline Atestado Neurológico/2016 & $\begin{array}{l}\text { "Atesto para devidos fins que XXXX foi atendido por mim devido à } \\
\text { Dislexia e TDAH. EX. fisio neurológico def cognitivo. Orientação } \\
\text { familiar. Avaliação e terapia com psicóloga. Sala reforço e e } \\
\text { recurso. Sugiro ritalina". }\end{array}$ \\
\hline
\end{tabular}

Fonte: Elaborado pelos autores

Aos 18 anos $\mathrm{J}$ refere que realizou atendimento clínico fonoaudiológico, com sessões de uma vez por mês, o qual interrompeu por não ter percebido avanços em relação à linguagem escrita.

A respeito de sua escolaridade, J. conta que após ter reprovado quatro vezes na $5^{\text {a }}$ série parou de estudar por sete anos. Refere, ainda, sem saber precisar exatamente quando, que depois de alguns anos, matriculou-se no Centro Estadual de Educação Básica para Jovens e Adultos para concluir o Ensino Fundamental II.

A partir disso, realizou duas vezes a prova do Exame Nacional do Ensino Médio para a conclusão do Ensino Médio (EM). Segundo J., em sua primeira participação, no referido exame, só foi aprovado na disciplina de matemática e, na segunda vez, nas demais disciplinas, recebendo assim certificação de conclusão do EM.

A partir desse momento, participou como cotista, na condição de deficiente, comprovada a partir de laudos de dislexia e TDAH, por quatro vezes do vestibular de uma Universidade Pública do Paraná, até ingressar num curso da área de ciências exatas e da terra. $\mathrm{Na}$ ocasião do vestibular pode solicitar e contar com a ajuda de um ledor e escriba e, depois de seu ingresso, foi encaminhado pelo Núcleo de Acessibilidade para atendimento fonoaudiológico por apresentar condições restritas de leitura e escrita.

Quanto ao processo terapêutico fonoaudiológico, objeto de nossa análise, cabe esclarecer que foi conduzido a partir dos seguintes objetivos: ressignificar as relações restritas e negativas estabelecidas por J. em torno das práticas de leitura e escrita e promover o avanço 
de suas condições de letramento. Para tanto, foram propostas práticas de leitura e escrita circunscritas a relações dialógicas envolvendo diferentes gêneros discursivos (carta, resumo, matéria de jornal, texto acadêmico, literatura, agenda). Tais atividades estiveram fundamentadas na perspectiva sócio-histórica, priorizando o trabalho fonoaudiológico com a linguagem escrita enquanto atividade discursiva e resultante de um trabalho coletivo e histórico.

Para a análise dos resultados foram reproduzidos trechos de diálogos ocorridos entre a terapeuta e o participante, bem como de produções escritas produzidas por J., durante as sessões fonoaudiológicas. Foram selecionados aqueles de maior relevância para atender aos objetivos desse estudo. O uso da letra T. sinaliza a participação da terapeuta e da letra J. a de João.

\section{Resultados e discussões}

No início do atendimento, J. afirmava, recorrentemente, que tinha muita dificuldade em ler e escrever, alegando ter vergonha, se sentir culpado, nervoso e constrangido durante tais práticas.

Diante das propostas de produções escritas apresentadas nas primeiras sessões terapêuticas, J. se recusava a ler e escrever solicitando à terapeuta para ser sua leitora e escriba. A partir de conversas em torno da sua recusa em ler e escrever, J. revelava não se reconhecer como escritor e leitor e que recorria, constantemente, a sua namorada para, em seu lugar, ocupar essa posição. Nesse sentido, contou que ela preenchia os dados no sistema da Universidade para realizar a sua matrícula nas disciplinas do curso, para escrever e-mails para professores e pessoas de setores da universidade, bem como, para a terapeuta para trocar informações sobre dias e horários de atendimento.

É interessante notar que, inicialmente, J. atribuía, também, à namorada o "mérito" de ter ingressado na Universidade, bem como de ter buscado ajuda fonoaudiológica para superar dificuldades em relação à leitura e escrita.

No início do processo terapêutico, J. apresentava uma visão contraditória no modo de analisar sua condição de leitor e escritor. Seus relatos eram atravessados, simultaneamente, por um viés medicalizante-reducionista-culpabilizante e por uma perspectiva crítica, conforme pode-se notar no Trecho I, abaixo descrito: 
Trecho I: 08/06/2017

L1. J: Lá em casa falam que eu sou o mais inteligente de todos...

L2. J: Mas só nesse ponto que eu deixei a desejar, de escrever, porque eu acho

L3. J: que fiquei relaxado, não escrevia, tinha alguma dificuldade ou distúrbio!

L4. T: Ficar relaxado quer dizer o que, aqui?

L5. J: /aaa/ não praticar! Eu não trabalhei a escrita...

L6. T: Então relaxado aqui é um defeito?

L7. T: (Risos)

L8. J: Realmente é um defeito.

L9. T: Acho que vale a pena refletir sobre isso...

L10. J: Tinha que ter me esforçado mais, trabalhado menos e ter estudado mais.

L11. Mas isso vem lá de trás, da escola, do meu conhecimento lá de trás.

L12. Escrita, foi atrasado!

A contradição manifesta nos enunciados acima descritos aponta para a noção de que J.: - ora se dizia como portador de distúrbios de leitura e escrita, reiterando o diagnóstico de dislexia e TDHA (anunciado nos laudos descritos no Quadro I), como problemas decorrentes de limitações inerentes e de natureza orgânica, perceptual, comportamental e cognitiva (L3, L6); - ora J. relacionava suas experiências com a linguagem escrita como relacionadas a determinantes mais amplos (L10, L11).

Pode-se notar que os diálogos estabelecidos entre J. e a terapeuta em torno de aspectos econômicos e educacionais envolvidos com a sua trajetória de vida, escolar e com seus processos de apropriação da linguagem, contribuíram para que ele passasse a reconhecer as suas dificuldades de leitura e escrita, para além de individuais, como social e coletivamente construídas.

Nota-se que a terapeuta, ao indagar J. se a falta de esforço e ser relaxado seria um defeito dele, embora tenha respondido que sim (L9), ele, também, relaciona “[...] o fato de ser o mais inteligente de todos, ter trabalhado pouco a escrita, ter deixado a desejar na escrita" com experiências vividas ao longo de sua vida. Ao afirmar que deveria "ter trabalhado" menos e inferir que deveria ter trabalhado mais na escrita, ele remete a sua relação com a escrita à sua condição econômica e familiar, pois, desde muito cedo, precisou trabalhar para contribuir com a renda da família, tendo então dificuldade em conciliar a escolaridade e o trabalho.

Evidenciando maior entendimento acerca das relações estabelecidas entre a sua condição de leitor e escritor e a trajetória escolar vivida, J., conforme Trecho II abaixo descrito, passa a assumir uma posição crítica frente ao sistema educacional ao qual esteve submetido, questionando normas e ações que resultaram na aprovação compulsiva de alunos (L1, L2) sem, contudo, garantir o aprendizado dos mesmos (L4, L5). 
Trecho II: 30/10/2017

L1 J: Não é fácil para mim ler tudo que pedem na universidade, fazer os

L2 J: trabalhos, dar conta de tudo, copiar a matéria.

L3 T: Por que você acha que isso acontece?

L4. J: Porque desde o início da minha carreira de escola a lei já me atingiu,

L5: não pode reprovar o aluno de $1^{a}$ a $5^{a}$ serie, tem que passar. Então em venho

L6: apanhando desde lá, eu já não fiz o fundamental, nem o médio, pulei direto

L7: de paraquedas, sem aprender para o ensino superior. Dai o aprendizado na

L8. Minha cidade é muito feia, é complicado.

Nos Trechos I e II pode-se apreender como J. vai incorporando em sua análise e, portanto, em seu discurso, aspectos - econômicos, familiares, educacionais - envolvidos com o modo como lê e escreve, evidenciando o deslocamento da posição de incapaz, culpado para uma posição crítica acerca do sistema educacional e pelas condições desfavoráveis de aprendizado instituídas. (L5, L6, L7).

Ressalta-se que a perspectiva sócio-histórica oferece elementos para o sujeito situar-se histórica e socialmente, desestabilizando visões que naturalizam e individualizam os processos de ensino-aprendizagem, bem como de apropriação e uso da escrita (SANTANA et al., 2016; GIROTO; ARAUJO; VITTA, 2019).

Cabe destacar que o processo clínico fonoaudiológico, orientado a partir de uma perspectiva que coloca em questão dicotomias estabelecidas entre o indivíduo/individual e a sociedade/social, bem como, as contradições e distintas posições ideológicas presentes nos discursos (BAKTHIN, 1990; GERALDI, 2013; ROJO; MELO, 2017), levou J. a questionar se as posições anunciadas nos laudos, nas avaliações e prescrições de tratamentos e remédios eram suficientes para explicar as desiguais e injustas condições materiais e subjetivas que fizeram parte de sua constituição enquanto sujeito, leitor e escritor e a superar as marcas de incapacidade, fracasso, sofrimento, impossibilidade, inferioridade deixadas pelas mesmas.

No início do processo terapêutico foi possível perceber que, atrelada à relação restrita e de sofrimento com a linguagem escrita, J. revelava ter contato e conhecimento restrito acerca de aspectos/particularidades discursivas, textuais e normativas pertinentes a diferentes gêneros discursivos. Contudo, os enunciados de J. situavam suas preocupações nas manifestações ortográficas fora do padrão e em atividades que poderiam eliminá-las. O medo de "escrever errado" justificava, segundo J., a sua resistência ou recusa em escrever textos que seriam endereçados a diferentes interlocutores e na sua insistência em solicitar atividades de ditado e de cópia. Inicialmente, a partir de tais atividades, J. passaria a apreender/decorar a ortografia e, a partir daí, poderia escrever textos para outras pessoas "sem falhas e/ou sintomas". 
Tal insistência revela a visão de J. como portador de uma doença, de um distúrbio que deveria ser curado para que pudesse ter uma relação positiva com a leitura/escrita e, por extensão, com as atividades envolvidas em sua formação acadêmica. Tal visão é atravessada por posições hegemônicas que circulam em discursos de autoridade, produzidos por profissionais da saúde e da educação, que reduzem a escrita a um código e seu aprendizado ao desenvolvimento de habilidades orgânicas-perceptuais (SIGNOR, 2012; GIROTO; ARAÚJO; VITTA, 2019).

Se, inicialmente, a prática da escrita estava condicionada ao "bom" desempenho ortográfico, ao longo do processo terapêutico, J. passou a compreender que escrever não é codificar e decodificar sons em letras e vice-versa, e que a apropriação da linguagem escrita não se dá a partir de atividades de repetição e memorização.

Tal mudança permitiu a J. direcionar sua atenção, também, para os aspectos discursivos e textuais que compõem a linguagem escrita e, nessa medida, passou a se surpreender com o fato de saber operar, de forma significativa, com tais aspectos. Para evidenciar esse movimento, segue abaixo a Produção I, fruto de uma proposta feita pela terapeuta para que J. escrevesse experiências difíceis e conflitantes vividas no contexto acadêmico, recorrentemente, referidas durante as sessões, as quais poderiam vir a compor um livro autobiográfico. J. aceitou "escrever" tais experiências, uma vez que pudesse ditá-las para que fossem "colocadas no papel" pela terapeuta.

Produção I (ditada, oralmente, por J. e escrita pela terapeuta) 08/06/2017:

L1. "Teve uma vez que em uma segunda-feira cheguei atrasado na sala de aula,

L2. estava tendo prova e eu não sabia o que fazer, se eu ficava na sala ou saia.

L3. Fiquei na sala, comecei a ler a prova, mas não conseguia escrever as

L4. respostas. Depois que todos sairram da sala falei para o professor que tinha

L5. dislexia. Ele todo assustado não sabia o que fazer para aplicar as avaliações

L6. para mim e perguntou o que eu achava melhor, respondi a ele que preferia

L7. oral. Ele então marcou em uma sala reservada só eu e ele e efetuou a prova.

L8. Filmou para ter o registro de como foi feito. Consegui demonstrar meu

L9. conhecimento para ele e consegui passar na matéria".

$\mathrm{Na}$ construção acima, pode-se notar que J. conhece características do gênero discursivo quanto à sua função, temática, estilo, assim como, aspectos estruturais capazes de garantir coesão e coerência. Nessa situação, foi possível notar que J. planejou, previamente, seu texto organizando, oralmente, partes e utilizando elementos de ligação e progressão textual que garantiram a apreensão do significado e a construção de sentidos (L2, L4, L5, L9) (GERALDI, 2013; KOCH; TAVAGLIA, 2006). Enfim, J. evidenciou ter acesso a recursos linguísticos que permitiram o manejo com aspectos discursivos e textuais próprios de um 
texto escrito, bem como reconhecer particularidades do relato autobiográfico (GERALDI, 2013; ROJO; MELO, 2017).

Apesar da recusa em produzir por escrito seu relato, justificada pelo desconhecimento ortográfico, J., ao ditá-lo para ser transcrito/escrito pela terapeuta, pode ocupar uma posição de autoria, organizar seu texto de forma a produzir efeitos de sentido nos seus interlocutores e, assim, os convocar a escutar suas dificuldades e necessidades vivenciadas durante sua formação acadêmica.

Ao ser confrontado com uma posição de autoria e com o seu saber em torno de aspectos discursivos e textuais, J. passou a rever a noção de que saber ler e escrever pressupõe, apenas, o domínio do sistema alfabético da língua, mas envolve o saber sobre as dimensões discursivas e textuais e, sobretudo, assumir uma posição de autoria.

Estudos desenvolvidos a partir da perspectiva adotada reiteram que o processo terapêutico, quando conduzido a partir de práticas de leitura e escrita que enfatizam a importância de o sujeito ocupar uma posição de autoria podem, assim como ocorreu com J., contribuir para que o sujeito diminua as resistências em relação à leitura e à escrita e passe a vivenciar, de forma efetiva e prazerosa, tais práticas (SIGNOR, 2012; SANTANA, 2016; GENTIL, 2016). Nessa direção, na medida em que J. passou a participar com maior autonomia de produções escritas, foi possível voltarmos as atenções para aspectos ortográficos, esclarecer que escritas fora do padrão não são erros, mas hipóteses próprias de um processo de apropriação, bem como analisar problemas e formas de enfrentamento relativos ao fato de o conhecimento ortográfico de J. não atender as demandas de uma escrita própria à formação no ES. Para tanto, foram realizadas discussões que pudessem oferecer elementos para a compreensão de como e porque a Educação Básica não garante a todos condições para avançar no domínio do aspecto ortografia da língua (GIROTO; ARAÚJO; VITTA, 2019).

Aspectos ortográficos também foram abordados durante a produção de J. da carta, abaixo apresentada, destinada a seus professores com o objetivo de relatar dificuldades enfrentadas no contexto acadêmico e propor estratégias para superá-las. 
Figura 1 - Produção Escrita II: 20/11/2017

$X X X X X, 20 / 11 / 2017$.

Professores,

Eu, $X X X X X X X$ de 26 anos passei na Universidade $X X X X X X$, no curso de $X X X X X$ e sou morador em $X X X X X X$.

Estou passando uma dificuldade no campus do $X X X$.

Na primeira fase do vestibular tinha professores capacitados e uma estrutura que me demonstraram muita confiança e depois fui aprovado para a segunda fase na qual eu passei.

No primeiro período do curso tinham sete matérias e nenhuma estrutura no XXX.

Enfrento muitos desafios e me sinto incapaz. Das sete matérias eu fui aprovado em cinco, sem apoio de um (a) profissional capacitado como tinha na $1^{\mathrm{a}}$ e $2^{\mathrm{a}}$ fase do processo seletivo da $X X X X$.

Além do apoio que estou tendo na Clínica de Fonoaudiologia da Universidade $X X X X$ para superar minhas dificuldades na leitura e na escrita, espero ter um acompanhamento na $X X X X$, como a lei permite.

Sendo assim, penso em algumas estratégias que podem me ajudar:

1. Ter um tutor no $\mathbf{X X X}$.

2. Ter mais tempo para realizar as provas.

3. Ter os materiais das disciplinas antes das aulas.

Obrigado a todos pela dedicação!

$X X X X X X X X$

Fonte: Acervo dos autores

A carta acima evidencia a posição de autoria que, ao longo do processo terapêutico, foi sendo assumida por J., uma vez que, por meio dela, promove o diálogo entre ele e os professores/educadores, expõe aspectos de sua trajetória particular e, ao mesmo tempo, os convoca a se comprometerem.

$\mathrm{Na}$ construção dessa carta, J. mostra conhecer características discursivas do texto produzido, ou seja, considerou seus interlocutores, o que desejava dizer aos mesmos, a finalidade de seu discurso, a temática envolvida e o estilo a ser adotado. $\mathrm{O}$ dito na carta evidencia que J. ampliou o seu entendimento acerca do que estava envolvido no enfrentamento de suas dificuldades de leitura e escrita, bem como avançou na apropriação 
dessa modalidade de linguagem. Enfim, J. deixa de atribuir a si as causas e a culpa de suas condições de leitura e escrita para abordá-las coletivamente, envolvendo a participação do corpo docente e da coordenação de seu curso.

É importante destacar que, se J. apresentou experiência e conhecimento durante a produção da referida carta, ao se deparar com a proposta de utilização de uma agenda, ele alegou não fazer uso, não saber como é organizada e estruturada e ter pouca familiaridade com esse suporte. Apesar disso, J. aceitou introduzir o uso sistemático da agenda e passou a compreender que uma de suas funções é organizar seu cotidiano, passando a registrar nela compromissos pessoais, profissionais e acadêmicos.

Tal situação evidencia que as intervenções fonoaudiológicas conduzidas a partir da relação com diferentes gêneros discursivos permitiram a J. conceber a escrita como uma modalidade de linguagem, a partir da qual são estabelecidas interações sociais e atividades humanas (SIGNOR, 2012; GENTIL, 2016; SIGNOR et al., 2018).

Cabe, ainda, destacar o fato de que o trabalho realizado com a escrita na agenda contribuiu, também, para o avanço na apropriação da ortografia. J. optou, por exemplo, escrever primeiramente numa folha à parte informações referentes às disciplinas que frequentaria naquele semestre para, após análise dos aspectos ortográficos, reescrevê-las na agenda, propriamente dita.

É interessante notar que J., inicialmente, parecia não reconhecer a agenda como uma produção cujo interlocutor seria ele mesmo e que teria o objetivo de registrar compromissos e fatos pessoais, caso contrário demonstraria uma menor preocupação com a ortografia Discussões acerca da importância diversificada que deve ser destinada à ortografia, dependendo dos contextos de produção da escrita, foram encaminhadas junto a J., durante as escritas na agenda, para que ele pudesse ampliar o seu entendimento sobre o fato de que os gêneros textuais implicam em modos de escritas diversificados, inclusive no que se refere aos aspectos normativos. A escrita na agenda propiciou diálogos e análises em retorno do fato de que textos que circularam em contextos públicos demandam uma maior preocupação com tais aspectos do que aqueles que circulam nas esferas privadas.

Considerando as análises realizadas, a partir das manifestações ortográficas fora do padrão produzidas por J., o mesmo passou a ampliar seu entendimento acerca dos critérios que regem o sistema alfabético da língua portuguesa. Enfim, passou a compreender que os ditos "erros" ortográficos, praticamente em sua totalidade, são decorrentes de hipóteses assentadas no apoio da oralidade, uma vez que as correlações estabelecidas entre sons e letras não são, quantitativa e qualitativamente, unívocas (FARACO, 2012). É importante destacar 
que um dos objetivos da terapia, quanto aos aspectos ortográficos, foi oferecer elementos para que J. passasse a analisar os motivos linguísticos que o levaram à construção de hipóteses fora do padrão e a concebê-las como parte do processo de apropriação e, portanto, previsíveis e necessárias (SIGNOR, 2012; GENTIL, 2016; SIGNOR et al., 2018).

Embora o processo terapêutico de J. tenha tido continuidade, visando avanço na apropriação e nos usos da linguagem escrita, os resultados acima analisados enfatizam que ele passou a assumir posição de autoria enquanto leitor e escritor, bem como a realizar análises e produções linguísticas próprias aos processos envolvidos com essa modalidade de linguagem, evidenciando, assim, as contribuições da orientação teórica no enfrentamento de abordagens e visões medicalizantes.

\section{Considerações finais}

Constatou-se, neste estudo, que a intervenção fonoaudiológica clínica, fundamentada na perspectiva sócio-histórica, promoveu o deslocamento da culpabilização e de uma perspectiva medicalizante, por parte do sujeito, no entendimento de suas restritas condições de leitura e escrita, pois J. passou a analisar criticamente a qualidade das interações negativas com e a partir da linguagem escrita em que esteve inserido e a repercussão das mesmas em sua história, experiências e em sua relação com a linguagem escrita. Tal ressignificação permitiu que J. reconhecesse e assumisse os seus desejos em ser um leitor e escritor "competente" e ocupasse um lugar de sujeito, capaz de elaborar hipóteses e entender a escrita como um processo contínuo.

A mudança da posição de $\mathrm{J}$. em relação à linguagem escrita denota que o atendimento clínico pautado em tal teoria, além de convocar o sujeito a ocupar um lugar de autoria diante de seus enunciados, em especial no contexto do qual faz parte, também contribui para seu avanço em relação aos aspectos discursivos, textuais e normativos da língua escrita.

A ressignificação das posições subjetivas frente à condição de leitor e escritor, ocorridas no estudo clínico em questão, é decorrente de um olhar e de uma posição dialógica promovida entre o terapeuta-fonoaudiólogo e o participante dessa pesquisa a qual, embora não predominante nas práticas clínicas, vem se mostrando capaz de promover a linguagem escrita junto a sujeitos considerados portadores de distúrbios e/ou patologias de leitura e escrita.

Nessa direção, é preciso ressaltar a necessidade e a importância de novos estudos, práticas e pesquisas direcionadas também à população acadêmica, no sentido de consolidar o 
papel do fonoaudiólogo com sujeitos encaminhados, cada vez mais, para atendimento clínico fonoaudiológico decorrente de supostas dificuldades de leitura e escrita que emergem durante sua formação no ES. Dessa forma, entendemos que o fonoaudiólogo, a partir de uma concepção de linguagem como constitutiva do sujeito e do compromisso em promover as condições de leitura e escrita aos alunos inseridos no ES, pode assumir papel importante na construção de uma sociedade mais igualitária, implementando práticas que contribuem com a democratização do ensino também envolvendo esse nível de formação.

\section{REFERENCIAS}

BAKTHIN M. Marxismo e filosofia da linguagem. São Paulo: Hucitec, 1990.

FARACO, C. A. Linguagem escrita e alfabetização. São Paulo: Ed. Contexto, 2012.

FERNANDES, D. F. C.; SANTOS, M. A. P.; BURIN, A. C. H. A questão do letramento na Universidade: algumas reflexões e desafios. Revista de Ciências Gerenciais, v. XII, n. 15, p. 75-84, 2008.

\section{GENTIL, M. A. O. Contribuição à crítica do trabalho da Fonoaudiologia Educacional à} luz da concepção histórico-cultural da linguagem: diante do crescente processo de medicalização e patologização da educação, que fazer? Orientador: Cláudio de Lira Santos Júnior. 2016. 260 f. Tese (Doutorado em Educação) - Universidade Federal da Bahia, Salvador, 2016.

GERALDI, J. W. Portos de passagem. 5. ed. São Paulo: Editora WMF Martins Fontes, 2013. GIROTO, C. R. M.; ARAUJO, L. A. A.; VITTA, F. C. F. Discursivização sobre "doenças do não aprender" no contexto educacional inclusivo: o que dizem os professores de educação infantil? Revista Ibero-Americana de Estudos em Educação, Araraquara, v. 14, n. esp. 1, p. 807-825, abr. 2019. DOI: https://doi.org/10.21723/riaee.v14iesp.1.12208

GOMES, A. (Org.). Letramento científico: sumário executivo de resultados. São Paulo: Instituto Paulo Montenegro, Ação Educativa, 2015.

INSTITUTO ABRAMUNDO. ILC - Indicador de Letramento Científico: Sumário executivo de resultados 2014. São Paulo: Fundação Carlos Chagas, 2014. 43 p.

KOCH, I. G. V. Ainter-ação pela linguagem. 8. ed. São Paulo: Contexto, 2003.

KOCH, I.; TRAVAGLIA, L. C. A coerência textual. São Paulo: Contexto, 2006.

LUSTOSA, S. S.; GUARINELlO, A. C; BERBERIAN, A. P.; MASSI, G. A. A. SILVA, D. V. Análise das práticas de letramento de ingressantes e concluintes de uma instituição de ensino superior: estudo de caso. Revista CEFAC, São Paulo, v. 18, p. 1008-1019, 2016. DOI: https://doi.org/10.1590/1982-021620161843716 
MANCEBO, D.; VALE, A. A. Políticas de expansão da educação superior no Brasil 19952010. Revista Brasileira de Educação, v. 20, n. 60, jan./mar. 2015.

MARINHO-ARAÚJO, C. M. Psicologia escolar na Educação Superior: novos cenários de intervenção e pesquisa. In: MARINHO-ARAÚJO, C. M. Psicologia Escolar novos cenários e contextos de pesquisa, prática e formação. 2. ed. Campinas: Alínea, 2015. p. 147-162.

MARQUESIN, D.F.B.; BENEVIDES, C.R. Leitura e Escrita no Ensino Superior. Revista Brasileira de educação, Rio de Janeiro, v. 14, n. 1, p. 9-28, 2011.

MORETTO, M. Tentativas de apropriação da linguagem acadêmica por estudantes universitários: A produção escrita na universidade. Comunicações, Piracicaba, v. 24, n. 1, p. 171-186, 2017.

MOYSES, M.A. A.; COLLARES, C. A. L. Controle e Medicalização da Infância. DESidades, v. 1, p. 1-5, 2013.

OLIVEIRA, E. C.; HARAYAMA, R. M.; VIÉGAS, L. S. Drogas e medicalização na escola: reflexões sobre um debate necessário. Revista Teias, Rio de Janeiro, v.17, n. 45, p. 99-118, 2016.

PAN, M.; LITENSKI, A. C. L. Letramento e identidade profissional: reflexões sobre leitura, escrita e subjetividade na universidade. Revista Psicologia Escolar e Educacional, São Paulo, v. 22, n. 3, p. 527-534, 2018.

PAN, M.A.G.S; ZUGMAN, M.J. Psicologia e políticas inclusivas na Educação Superior: contribuições de uma leitura bakhtiniana. Estudos e Pesquisas em Psicologia, Rio de Janeiro, v. 15, n. 1, p. 135-154, 2015

ROJO, R.; MELO, R. Letramentos contemporâneos e a arquitetônica Bakhtiniana. DELTA, São Paulo, v. 33, p. 1271-1289, 2017. DOI: https://doi.org/10.1590/0102-445057781725543649

SANTANA, A. P. O. DONIDA, L. O. MONTEIRO, A. L. C. P. SILVA, S. M. Acessibilidade e permanência: um estudo do programa institucional de apoio aos estudantes da Universidade Federal de Santa Catarina. Revista Ibero-Americana de Estudos em Educação, Araraquara, v.10, n. esp., p. 673-689, 2016. DOI: https://doi.org/10.21723/riaee.v10i5.7919

SIGNOR, R. C. F. Terapia fonoaudiológica em grupo voltada à linguagem escrita: uma perspectiva dialógica. RBLA, Belo Horizonte, v. 12, n. 3, p. 585-605, 2012.

SIGNOR, R. C. F; VIEIRA, S. K.; BERBERIAN, A. P.; SANTANA, A. P. Distúrbio de processamento auditivo x dificuldade de leitura e escrita: há uma relação? Revista Brasileira de Linguística Aplicada, Belo Horizonte, v. 18, n. 3, p. 581-607, 2018. DOI: http://dx.doi.org/10.1590/1984-6398201813079 


\section{Como referenciar este artigo}

VIEIRA, S. K.; TONOCCHI, R. C.; BERBERIAN, A. P. Promoção do Letramento X medicalização no Ensino Superior: contribuições de uma abordagem fonoaudiológica. Revista Ibero-Americana de Estudos em Educação, Araraquara, v. 15, n. esp. 5, p. 29672984, dez. 2020. e-ISSN: 1982-5587. DOI: https://doi.org/10.21723/riaee.v15iesp5.14569

Submetido em: 10/01/2020

Revisões requeridas em: 25/05/2020

Aprovado em: $30 / 10 / 2020$

Publicado em: 01/12/2020 